\title{
Fates of CD4+ $\mathbf{T}$ Cells in a Tolerant Environment Depend on Timing and Place of Antigen Exposure
}

\author{
B. E. Burrella and J. S. Bromberga,b,c, ${ }^{*}$ \\ ${ }^{a}$ Center for Vascular and Inflammatory Diseases, University of Maryland School of Medicine, \\ Baltimore, MD \\ ${ }^{b}$ Department of Surgery, University of Maryland School of Medicine, Baltimore, MD \\ 'Department of Microbiology and Immunology, University of Maryland School of Medicine, \\ Baltimore, MD
}

\begin{abstract}
In experimental organ transplantation, tolerance is induced by administration of anti-CD40L mAb in conjunction with donor-specific splenocyte transfusion. Multiple, sometimes conflicting mechanisms of action resulting from this treatment have been reported. To resolve these issues, this study assessed the fates of graft reactive cells at different times and locations in the tolerant environment. Alloantigen-specific $\mathrm{CD} 4^{+} \mathrm{T}$ cells transferred at time of tolerance induction $(7$ days before transplantation) became activated, expressed CD69 and CD44, and proliferated. Importantly, a large subset of this population became Foxp $3^{+}$, more so in the lymph nodes than spleen, indicative of differentiation to a regulatory phenotype. In contrast, graft reactive $\mathrm{CD} 4^{+} \mathrm{T}$ cells transferred to tolerogen-treated recipients at the time of transplantation failed either to proliferate or to differentiate, and instead were deleted via apoptosis. In untreated rejecting recipients graft reactive $\mathrm{CD} 4^{+} \mathrm{T}$ cells became activated, proliferated and differentiated mainly in the spleen, and many of these cells were eventually deleted. These data resolve many apparent contradictions in the literature by showing that the timing of antigen exposure, the immunologic status of the recipients and secondary lymphoid organ location act together as key factors to determine the fate of graft reactive $\mathrm{CD} 4^{+} \mathrm{T}$ cells.
\end{abstract}

\section{Keywords}

Alloreactive $\mathrm{T}$ cells; $\mathrm{CD} 4^{+} \mathrm{T}$ cells; $\mathrm{T}$-cell activation; tolerance; transplantation

\section{Introduction}

\begin{abstract}
Long-term allograft acceptance and donor-specific tolerance remain elusive goals. Several experimental protocols induce tolerance using a variety of costimulatory inhibitors $(1,2)$ and antirejection drugs (3). The common threads among these modes of tolerance induction include targeting T-cell presence (4), activation (2,5), and/or homing (6). These targets are not necessarily mutually exclusive. Indeed, a consistent theme of tolerance induction protocols is the concurrent use of multiple therapies that affect the fates of $\mathrm{T}$ cells (3).
\end{abstract}

\footnotetext{
(C) Copyright 2011 The American Society of Transplantation Wiley Periodicals Inc.

*Corresponding author: Jonathan S. Bromberg, jbromberg@ smail.umaryland.edu.

Disclosure

The authors of this manuscript have no conflicts of interest to disclose as described by the American Journal of Transplantation.
} 
One promising approach for donor-specific tolerance is the combination of donor-specific splenocyte transfusion (DST) and CD40-CD40L costimulatory blockade (7). Anti-CD40L $\mathrm{mAb}$ was originally described as blocking $\mathrm{CD} 4^{+} \mathrm{T}$-cell help for B-cell activation (8), and when administered in conjunction with DST long-term graft survival was achieved $(9,10)$. However, the reported mechanism(s) by which anti-CD40L mAb induces allograft tolerance, and likewise, the fate(s) of graft reactive cells in tolerogen-treated recipients are varied and remain to be fully elucidated. It is suggested that anti-CD40L mAb has no impact on the activation of graft reactive cells when administered alone, but prevents graft rejection when administered in conjunction with DST or alloantigen before transplantation (11). However, others routinely use solely anti-CD40L mAb therapy and achieve long-lasting graft survival (12-14). One study with a cardiac allograft model suggests that DST in conjunction with anti-CD40L mAb deletes donor reactive T-cells and found no evidence for regulatory T-cell generation (11). Conversely, DST and anti-CD40L mAb has been reported to induce (15) and/or augment regulatory $\mathrm{T}$ cell $\left(\mathrm{T}_{\mathrm{reg}}\right)$ function and dampen graft reactive cell responses (1). Others have found anti-CD40L mAb to maintain graft reactive cells in an anergic state without deleting them $(12,14)$. Further reports found anti-CD40L mAb to mark graft reactive cells for deletion by complement fixation $(16,17)$, though anti-CD40L mAb remains effective in the absence of C1q (18). CD40L blockade may also skew T-cell responses away from typically dominant Th1-Th2 responses (10). The resulting Th2 responses prevent CD8 cells from rejecting the graft (19) and/or mediate peripheral tolerance (20). Anti-CD40L mAb may also form a physical barrier to prevent activation signals and effector function $(21,22)$ and/or induce apoptosis (23). In a model of GVHD, anti-CD40L mAb therapy allowed graft reactive $\mathrm{CD} 8^{+}$cells to proliferate, become activated and subsequently be deleted by apoptosis (24). Although some of these diverse findings may be based on differences in model systems, a unifying understanding of the fates of graft reactive cells remains elusive.

This study was undertaken to assess fates of graft reactive cells both during the generation of tolerance and later on in a tolerant environment. Cohorts of labeled graft reactive cells were transferred to tolerogen-treated transplant recipients, either at the time of tolerance induction and/or at the time of graft placement. When transferred at the time of induction, populations of graft reactive cells proliferated, became activated, differentiated into regulatory cells and became apoptotic. These fates were found in varying degrees throughout secondary lymphoid organs, but predominated in lymph nodes (LN) in comparison to spleen. In contrast, graft reactive cells transferred at the time of transplantation remained quiescent and became apoptotic, and driving these cells into or out of the LN did not alter their fate. These data suggest that the timing of antigen encounter and the immunological environment of the recipient, along with secondary lymphoid organ function, play decisive roles in determining the fates of an otherwise homogeneous cohort of graft reactive cells.

\section{Materials and Methods}

\section{Mice}

C57BL/6 $\left(\mathrm{H}-2^{\mathrm{b}}, \mathrm{CD} 45.2^{+}\right)$, B6.SJL $\left(\mathrm{H}-2^{\mathrm{b}}, \mathrm{CD} 45.1^{+}\right)$and BALB/c $\left(\mathrm{H}-2^{\mathrm{d}}\right)$ mice were purchased from the Jackson Laboratory. C57BL/6 Foxp3-DTR and T-cell receptor (TCR)transgenic (Tg) TEa mice (25) were from A. Y. Rudensky (Memorial Sloan Kettering Cancer Center, New York, NY, USA). All mice were housed under specific pathogen-free conditions. Mice used were between 6 and 12 weeks of age. All experiments were performed with age- and sex-matched mice in accordance with protocols approved by the Institutional Animal Care and Utilization Committee. 


\section{Vascularized heterotopic cardiac transplantation}

C57BL/6 $\left(\mathrm{CD} 45.2^{+}\right)$or B6.SJL $\left(\mathrm{CD} 45.1^{+}\right)$mice were transplanted with intact BALB/c cardiac allografts, as described (26). Transplant function was monitored by abdominal palpation.

\section{Tolerance induction, cell transfer and in vivo treatments}

To induce tolerance, mice received DST of $10^{7} \mathrm{BALB} / \mathrm{c}$ splenic lymphocytes on day -7 and $250 \mu \mathrm{g}$ anti-CD40L mAb (clone MR1, purified by BioXCell, West Lebanon, NH, USA) intravenously (i.v.) on days $-7,-4,0$ and 4 relative to transplant on day 0 . CD4+ TEa TCR $\mathrm{Tg} \mathrm{T}$ cells were purified from pooled splenic and $\mathrm{LN}$ lymphocytes using the $\mathrm{CD} 4^{+}$negative selection EasySep kit according to the manufacturer's instructions (Stemcell Technologies, Vancouver, BC, Canada). Cells were then checked for purity (>90\%) and labeled with CFSE (Invitrogen, Carlsbad, CA, USA) or eFluor 670 (eBioscience, San Diego, CA, USA) according to manufacturer's instructions. As indicated, on days -7 or 0 relative to transplant, $2 \times 10^{7}$ cells were transferred i.v. to recipients. Anti-CD62L (clone MEL-14, American Type Culture Collection, Manassas, VA, USA), was grown in culture, supernatant purified over protein-A columns (Amersham Biosciences, Piscataway, NJ, USA) and administered $(100 \mu \mathrm{g} /$ mouse i.v.) on days 0 and 1, as indicated. FTY720 (gift of Dr. V. Brinkmann, Novartis, Basel, Switzerland) was administered daily from day 0 to day $6(25 \mu \mathrm{g} / \mathrm{mouse}$ via oral gavage) as indicated. To deplete $\mathrm{CD} 25^{+}$cells, mice received $100 \mu \mathrm{g}$ of anti-CD25 mAb (clone PC61, purified by BioXCell, West Lebanon, NH, USA; Ref. 27) i.v. 6 days before transfer of day 0 cells and second dose of DST and anti-CD40L mAb. To deplete Foxp3 ${ }^{+}$ cells, Foxp3-DTR mice received $50 \mu \mathrm{g} / \mathrm{kg}$ diphtheria toxin i.v. 2 days before transfer of day 0 cells and second dose of DST and anti-CD40L mAb.

\section{Cell preparations}

Spleens and LN were removed and processed through 30- $\mu$ m-pore size nylon mesh into single-cell suspensions. RBC were removed from splenic samples by ACK lysis (Lonza, Basel, Switzerland). Transplanted hearts were removed, pooled, minced and digested with 1 $\mathrm{mg} / \mathrm{mL}$ collagenase A (Roche, Indianapolis, IN, USA) for $30 \mathrm{~min}$ at $37^{\circ} \mathrm{C}$. Tissue debris was allowed to settle at $1 \times \mathrm{g}$, and the suspension containing graft infiltrating cells (GIC) was recovered by pipette. Red blood cells (RBC) were removed by ACK lysis, and GIC were passed through a $30-\mu \mathrm{m}$-pore size nylon mesh. All cells were resuspended in $1 \times$ phosphate buffered solution (PBS) and viable leukocytes were enumerated by trypan blue exclusion.

\section{Flow cytometry}

Anti-CD45.2 (clone 104) APC-Cy7; anti-CD44 (clone IM7) APC-Cy7 and PE-Cy7; antiCD69 (clone H1.2F3) APC-Cy7 and PE-Cy7; anti-CD4 (clone RM4-5) PE, PercP and PercP-Cy5.5, anti-CD25 (clone PC61) FITC and PE-Cy7; anti-CD62L (cone MEL-14) APC-Cy7 and anti-Foxp3 (clone FJK-16s) PE were obtained from eBioscience. Annexin V $\mathrm{PE}$ and 7-AAD were obtained from BD Biosciences (San Diego, CA, USA). Cells were acquired for flow cytometry on a FACSCanto II or Fortessa II (BD Biosciences) using FACSDiva software (BD Biosciences). Flow cytometric data was analyzed using FlowJo v. 8.8.7 (TreeStar Inc., Ashland, OR, USA).

\section{Statistical analysis}

Data were analyzed with GraphPad Prism 4.0c software using Student's paired or unpaired $t$-tests with Welch's correction as appropriate. p-Values of $\$ 0.05$ were considered statistically significant. 


\section{Results}

\section{Method for determining the fates of graft reactive cells}

To track the fate of graft reactive cells, we utilized a transfer model with TCR Tg CD4 ${ }^{+}$ cells from TEa mice that recognize donor I- $E^{d}$ presented by recipient I-A ${ }^{b}$ (Figure $1 A$ ). As expected, upon isolation these TCR Tg T cells display a naive phenotype as assessed by flow cytometry, expressing low levels of activation and regulatory T-cell markers and low levels of Foxp3 (Figure 1C; Ref. 28). These cells were labeled with CFSE and $2 \times 10^{7}$ transferred i.v. into C57BL/6 recipients 7 days before receiving a cardiac allograft (day -7 cells). On the day of transplant, another cohort of $2 \times 10^{7} \mathrm{TEa}$ cells labeled with eFluor 670 were transferred i.v. into the same recipients (day 0 cells). To induce tolerance, mice received DST (i.v. transfusion of $10^{7}$ donor BALB/c splenocytes) on day -7 in conjunction with anti-CD40L mAb $(250 \mu \mathrm{g} /$ dose i.v. $)$ on days $-7,-4,0$ and +4 . Rejecting mice received TEa cells but no tolerogen. With this model, the fates of graft reactive cells exposed to alloantigen either at the time of tolerance induction (day -7 cells, CFSE) or at the time of transplantation (day 0 cells, eFluor) were tracked within the same recipient. Proliferation of the two cell cohorts was tracked by dye dilution, and cells that had proliferated to the point of diluting out dye were tracked by using CD45 congenic markers. Flow cytometry data are represented as the percentage of viable label ${ }^{+}$or marker $^{+}, \mathrm{CD}^{+}$, singlet lymphocytes; the gating scheme is depicted in Figure 1B. This model is novel in comparison to other studies $(11,29-32)$ in that by adoptively transferring fluorescently labeled, congenic TCR Tg CD4+ cells, the fates of both unproliferated and highly proliferated alloreactive cells could be examined both at the time of tolerance induction and at the time of transplantation in a nonlymphopenic recipient.

\section{Graft reactive cells proliferate and become activated in response to DST and anti-CD40L before transplantation}

To assess the initial impact of DST and anti-CD40L mAb tolerogen treatment on alloreactive cells, CD45. $1^{+}$mice received eFluor labeled TEa cells $\left(\mathrm{CD} 45.2^{+}\right)$on day -7 in conjunction with DST and anti-CD40L mAb. Mice were euthanized on days $-6,-4,-2$ and 0 relative to transplant (days 1, 3, 5 and 7 after cell transfer), and spleen and $\mathrm{LN}$ lymphocytes recovered for analysis by flow cytometry. In the spleens (Figure 2A) and LN (Figure 2B) of tolerogen-treated mice, alloreactive cells upregulated CD69 and CD44 and downregulated CD62L by day -4 , signifying acute activation of these cells. Further, alloreactive cells, in the LN more so than spleen, expressed both CD25 and Foxp3, indicative of adaptive $\mathrm{T}_{\text {reg }}$ generation. Expression of acute activation markers decreased whereas $T_{\text {reg }}$ markers became more pronounced as tolerance induction proceeded towards day 0 , the time of transplantation. These data showed that by the time of transplantation at day 0 , tolerance induction was associated with both the activation and $\mathrm{T}_{\text {reg }}$ conversion of alloreactive cells.

Proliferation of alloreactive cells was analyzed by dilution of cell label (Figures $2 \mathrm{C}$ and D). Proliferation was evident by day -4 , with proliferation more pronounced in the spleen as compared to the $\mathrm{LN}$ at all time-points examined. Viability was analyzed by annexin $\mathrm{V}$ and 7-AAD staining (Figure 2E). Cells were mostly viable on day -4 whereas by day $-2, \sim 40 \%$ and $80 \%$ of the alloreactive cells in the spleen and LN, respectively, were apoptotic, likely as a result of activation induced cell death (AICD; Ref. 33). Interestingly, the percentage of un-proliferated cells in the spleen increased over time, suggesting that proliferating cells were deleted by apoptosis or moved out of the spleen. Taken together, these data showed that alloreactive cells undergo acute activation, proliferation and either apoptosis or conversion to $\mathrm{T}_{\text {reg }}$ following tolerance induction with preferential $\mathrm{T}_{\text {reg }}$ conversion and apoptosis in the LN. 


\section{Graft reactive cells proliferate and become activated following treatment with DST alone}

To assess the impact of DST in the absence of anti-CD40L mAb, CD45.1 $1^{+}$congenic mice received labeled TEa cells $\left(\mathrm{CD} 45.2^{+}\right)$and DST alone. Similar to tolerogen-treated mice, alloreactive cells became activated (upregulated CD69 and CD44 while downregulating CD62L) by day -4 (Figures 3A and B). However, alloreactive cells expressed CD25 but not Foxp3, indicative of activation with- out $\mathrm{T}_{\text {reg }}$ conversion. Proliferation was evident by day 4 and was equivalent in the spleen and LN (Figures 3C and D). By day -2 , almost all cells had undergone at least one round of proliferation. Cells were mostly viable on day -4 , however, by day $-2 \sim 40 \%$ and $70 \%$ of cells in the spleen and LN, respectively, were apoptotic.

Taken together, these data showed that following antigen exposure in the absence of costimulatory blockade alloreactive cells undergo acute activation and proliferation without conversion to $\mathrm{T}_{\text {reg. }}$. Following acute activation, many cells were deleted by AICD-associated apoptosis (33). Thus, costimulatory blockade w s a key determinant for the generation of antigen-specific $\mathrm{T}_{\text {reg }}$, further underlining the importance of anti-CD40L therapy in inducing graft tolerance.

\section{Graft reactive cells transferred at day -7 undergo phenotypic changes in response to tolerance induction and transplantation}

To assess phenotypic changes in the day -7 graft reactive cells after transplantation, tolerogen-treated recipients were euthanized on days 1,3,5 and 7 posttransplant and graft reactive cells analyzed by flow cytometry. In the spleens of tolerogen-treated mice (Figure 4A), graft reactive cells upregulated CD69 and CD44 and down modulated CD62L. A significant portion of this population expressed CD25 and Foxp3, showing that many of these cells became $\mathrm{T}_{\text {reg. }}$. This pattern of activation and regulatory cell marker expression in splenic T cells was mirrored in the LN (Figure 4B). Importantly, although about $25 \%$ of the splenic day -7 cells became Foxp $3^{+}$by day 1 , about $50 \%$ of the LN day -7 cells expressed this marker. This observation supports previous observations (34) that the LN is integral to the generation of adaptive $\mathrm{T}_{\text {reg }}$. These data also showed that despite being exposed to tolerogen as a homogeneous population, graft reactive cells skew toward different lineages, and that secondary lymphoid organ location is a major determinant of lineage commitment.

Day -7 cells proliferated vigorously (Figures $4 \mathrm{C}$ and $\mathrm{D}$ ), with several rounds of division evident by day 1 posttrans-plant and continuing on to at least day 7 . Thus, despite costimulatory blockade, cells recognized alloantigen and proliferated. These data argued against the hypothesis that graft reactive cells were all rendered anergic or deleted by complement following anti-CD40L mAb therapy $(16,17)$.

Alloreactive TEa cell apoptosis was assessed using both CFSE and CD45.2 expression. For the entire cohort of CD45.2 $2^{+}$cells on day 1 , the majority of transferred cells were viable (Figure 4E, top) and retained their CFSE label (Figure 4F). Most graft reactive day -7 cells in the spleen ( $\sim 90 \%), \mathrm{LN}(\sim 80 \%)$ and graft $(\sim 80 \%)$ that maintained CFSE label $\left(\mathrm{CFSE}^{+}\right)$ also remained viable (annexin $\mathrm{V}^{-}, 7-\mathrm{AAD}^{-}$, Figure $4 \mathrm{E}$, middle). Focusing on highly proliferated CFSE- cells, the majority of these cells in the spleen ( 75\%) and LN ( $90 \%)$ were either early (annexin $\mathrm{V}^{+}, 7-\mathrm{AAD}-$ ) or late apoptotic (annexin $\mathrm{V}^{+}, 7-\mathrm{AAD}^{+}$, Figure $4 \mathrm{E}$, bottom), suggesting AICD. Most $\mathrm{CFSE}^{-}$day -7 cells located in the grafts of tolerogentreated recipients remained viable ( $\sim 80 \%$, Figure $4 \mathrm{E})$.

These data showed that tolerance induction resulted in the activation of graft reactive cells. After the initial wave of apoptosis before transplantation (Figure 2E), most cells persisted whereas some highly proliferated cells underwent AICD (Figure 4E). A large portion of the persistent cells became $\mathrm{T}_{\text {reg }}$, and this phenotype was more pre-dominant in $\mathrm{LN}$ compared to 
spleen. Graft reactive cell apoptosis was barely evident in the graft, whereas appreciable apoptosis was observed in secondary lymphoid organs, and more so in LN. As adaptive $T_{\text {reg }}$ induction occurs preferentially in LN (34), graft reactive non- $\mathrm{T}_{\text {reg }}$ cells in this location may be deleted more readily than graft reactive cells in other tissues. These findings further support the notion that $\mathrm{LN}$ is an important site of immunologic control.

\section{Graft reactive cells exposed to antigen in a tolerant environment do not become activated}

To assess phenotypic changes in graft reactive cells present at the time of transplantation in tolerogentreated recipients, mice received TEa cells on day 0 . These day 0 cells were readily detected in both the spleen (Figure 5A) and LN (Figure 5B), and only a small percentage expressed either activation or regulatory markers. These findings were significantly different compared to day -7 cells that differentiated into $\mathrm{T}_{\text {reg }}$ (compare Foxp $3^{+}$cells in Figures $4 \mathrm{~A}$ and B-Figures 5A and B). These data showed that by the time of transplantation, an environment had been established that inhibited graft reactive cells from becoming activated and developing into either effector or regulatory lineages.

The cells transferred on day 0 also failed to proliferate (Figures $5 \mathrm{C}$ and D), in contrast to cells transferred on day -7 , in which substantial proliferation was detected (compare with Figures $2 \mathrm{C}$ and $\mathrm{D}-4 \mathrm{C}$ and $\mathrm{D}$ ). Day 0 cells did not activate or proliferate in the absence of the day -7 cell transfer, showing that day 0 cell quiescence was not due to interference by an excessive number of TCR Tg cells in these recipients (data not shown). These findings further argued against the hypothesis that activated cells were deleted by complement following anti-CD40L mAb therapy $(16,17)$.

A large percentage of day 0 transferred cells became apoptotic in the spleens, LN, and grafts of tolerant recipients (Figure 5E), despite the majority of these cells retaining their CFSE label (Figure 5F). Apoptosis was still observed when separately analyzing the predominant $\mathrm{CFSE}^{+}$and the small $\mathrm{CFS}^{-}$populations. These findings showed that cells exposed to antigen at the time of transplantation in tolerogen-treated mice were in a quiescent state before deletion via apoptosis. Deletion may have been due to $\mathrm{T}_{\text {reg }}$ involvement (35-38), lack of costimulatory signals $(21,22,39)$, and/or incorrect positioning in lymphoid structures (data not shown; Ref. 40).

\section{Graft reactive cells undergo phenotypic changes in response to rejection}

To assess changes in graft reactive cells in response to unimpeded alloantigen stimulation and rejection, untreated recipients received TEa T cells on day -7 . These cells acquired an acutely activated phenotype with increased CD44 and CD69 and decreased CD62L (Figures $6 \mathrm{~A}$ and $\mathrm{B}$ ). In contrast to day -7 cells in tolerized recipients, a negligible percentage of these cells became Foxp ${ }^{+}$, showing that the vast majority of these cells became effectors.

Day -7 cells began to proliferate in the spleen (Figure 6C) by day 5 posttransplant, commensurate with no exposure to alloantigen until day 0 . There was little proliferation of these cells in the LN (Figure 6D). These findings again supported the notion that lymphocyte residence and pro-liferation in the $\mathrm{LN}$ were vital to $\mathrm{T}_{\text {reg }}$ development (34), whereas effector $\mathrm{T}$ cell development primarily occurred in the spleen $(41,42)$.

Assessment of apoptosis showed that $\mathrm{CFSE}^{+}$cells, which were either un-proliferated or only moderately proliferated, remained viable (Figure 6E), but represented the minority of CD45. $2^{+}$cells (Figure 6F). Highly proliferated, CFSE-CD45.2+ cells were mostly either early (annexin $\mathrm{V}^{+}, 7-\mathrm{AA}^{-}$) or late apoptotic (annexin $\left.\mathrm{V}^{+}, 7-\mathrm{AAD}^{+}\right)$in the spleen $(\sim 75 \%)$ and LN ( $\sim 90 \%)$. Most day -7 cells in the grafts remained viable $(\sim 90 \%$, Figure $6 \mathrm{E})$. These data showed that concurrent with rejection, graft reactive cells became activated, proliferated, and many were deleted, likely due to AICD (43). In stark contrast to tolerogen- 
treated recipients, graft reactive cells in rejecting recipients failed to differentiate into $T_{\text {reg }}$, despite similar numbers of cells in the spleens and $\mathrm{LN}$ of rejecting and tolerogen-treated recipients ( $p>0.05$ for number of cells in spleen and $\mathrm{LN}$ in tolerant vs. rejecting groups).

To address the issue of a lack of exposure to alloantigen in vivo in the day -7 cohort, phenotypic changes in graft reactive cells transferred at the time of transplantation (day 0) to rejecting mice were also assessed. Similar to observations made with the day -7 cells, day 0 cells acquired an activated phenotype with increased CD44 and CD69 and decreased CD62L (Figures 7A and B). A negligible percentage of these cells became Foxp $3^{+}$, showing that the majority became effectors.

Day 0 cells underwent substantial proliferation in the spleen by 5 days posttransplantation (Figure 7C), whereas proliferation was less and lagged behind in the LN (Figure 7D), again supporting the notion that alloantigen presentation and immunogenic interactions occurred primarily in the spleen.

Analyzing the total cohort of $\mathrm{CD} 45.2^{+}$graft reactive cells, or the $\mathrm{CFSE}^{+}$or $\mathrm{CFS}^{-}$subsets, the majority of graft reactive cells remained viable (Figure 7E) and $\mathrm{CFSE}^{+}$(Figure 7F). Sizeable percentages of both early and late apoptotic cells were apparent, and more so in LN than spleen. Apoptosis was also readily detectable within the graft. These findings suggest that by day 5 after transplant, many stimulated graft reactive cells underwent AICD (43).

\section{Lymph node occupancy fails to convert day 0 cells into $\mathrm{Foxp}^{+}$cells}

To dissect signals exerted on day 0 cells that prevented cells from becoming activated and/or Foxp $3^{+}$, whereas day -7 cells became Foxp $3^{+}$, we hypothesized that the niche for regulatory cells was "full" and prevented day 0 cells from acquiring this phenotype. To test this hypothesis, regulatory cells were depleted by administering anti-CD25 mAb (27) to tolerogen-treated recipients. Following $\mathrm{CD} 25^{+}$cell depletion, day 0 cells still failed to become Foxp $3^{+}$(data not shown). Of note, this treatment did not completely deplete the Foxp $3^{+}$cell compartment despite completely coating $\mathrm{CD} 25^{+}$cells with $\mathrm{mAb}$, and some $\mathrm{mAb}$ likely remained in circulation at day 0 .

To deplete regulatory $\mathrm{T}$ cells more completely and specifically, Foxp3-DTR mice were tolerized starting on day -7 and received diphtheria toxin (DT) on day -2 , which effectively depleted endogenous $\mathrm{T}_{\text {reg }}$ (data not shown). Labeled TEa cells transferred on day 0 , in conjunction with DST and anti-CD40L mAb, again failed to convert to a regulatory phenotype, suggesting that a "full niche" was not responsible for this outcome (data not shown).

$\mathrm{LN}$ occupancy is required for Foxp $3^{+}$regulatory cell generation (34) and the results presented in Figures 3-7 demonstrated the preference of $T_{\text {reg }}$ and effector cell generation for the $\mathrm{LN}$ and spleen, respectively. We hypothesized that driving day 0 graft reactive cells into the $\mathrm{LN}$ of tolerogen-treated mice would result in the generation of Foxp $3^{+}$day 0 cells. Conversely, we hypothesized that preventing day 0 cells from entering the LN of tolerogentreated mice would lead to a failure in regulation of these cells, resulting in their activation and proliferation. To test this hypothesis, 7 days after initiating tolerogen treatment with DST and anti-CD40L mAb, recipients were re-challenged with al-loantigen by administering a second DST, in conjunction with a second transfer of TEa cells. To prevent cells from entering $\mathrm{LN}$, mice were treated with a blocking anti-CD62 $\mathrm{L}$ mAb on days 0 and 1 . To force the retention of cells in the LN, mice were treated with the sphingosine 1phosphate receptor 1 modulator FTY720 on days 0-6. Peripheral blood lymphocyte counts for each treatment group confirmed predicted reagent functionality, so that anti-CD62L mAb increased and FTY720 decreased, peripheral lymphocyte counts (data not shown). 
Day -7 cells became activated $\left(\mathrm{CD} 69^{+}\right.$and $\left.\mathrm{CD}^{4} 4^{+}\right)$and converted to Foxp3 ${ }^{+} \mathrm{T}_{\text {reg }}$ in the spleen and LN (data not shown), whereas day 0 cells failed to undergo phenotypic changes (Figure 8, black bars). Day 0 cells forced out of the LN by anti-CD62L mAb did not upregulate CD69 or CD44 expression (Figure 8A, gray bars and data not shown), suggesting that in mice already treated with tolerogen, LN occupancy was dispensable for the prevention of graft reactive cell activation. Conversely, forced LN occupancy with FTY720 did not induce CD69, CD44, or Foxp3 expression in day 0 cells (Figure 8B, lined bars and data not shown), suggesting that LN occupancy was not solely responsible for T-cell activation with subsequent $T_{\text {reg }}$ generation. Hence, regulation of day 0 cells did not require LN occupancy, and LN occupancy in conjunction with DST and anti-CD40L mAb therapy did not guarantee $\mathrm{T}_{\text {reg }}$ induction.

\section{Discussion}

Our data demonstrated that graft reactive cells had distinct fates depending on the timing and environment of antigen exposure. Cells transferred at the time of alloantigen exposure and CD40L blockade proliferated, became activated, and differentiated into $\mathrm{T}_{\text {reg }}$, whereas cells transferred into an established tolerant environment at the time of transplantation remained quiescent without activation and were deleted via apoptosis. Furthermore, cell fate also depended on migration to secondary lymphoid organs, so that converted $\mathrm{T}_{\text {reg }}$ were detected primarily in $\mathrm{LN}$ rather than spleen, whereas in rejecting recipients cell activation and priming preferentially occurred in the spleen instead of LN.

These data expand upon previous studies demonstrating that antigen-specific cell fate following antigen exposure is dependent upon numerous factors. High T-cell clonal frequency results in a greater expansion of this population after activation (44). However, a small clonal number of $\mathrm{T}$ cells results in greater longevity and activation potential of the clone (45). TCR avidity $(46,47)$ and affinity $(48)$ affect T-cell responses. Two subsets are distinguishable among high-avidity T cells: one which undergoes AICD and one that is both anergic and regulatory (47). High-avidity T cells tend toward Th1 differentiation (46) and mount protective Th1 responses (48). In contrast, low-avidity cells are resistant to AICD (47), differentiate in a Th2 direction (46) and mount a "non-healer" Th2 response (48). The route of antigen exposure also plays a role, as i.v. administration results in a Th1 response and memory generation, whereas intranasal exposure results in a short-lived Th17 response (49). To this list, we now add secondary lymphoid organ migration and timing of environmental exposure.

In allograft tolerance, there are four common threads repeated throughout the literature. Although these themes may sometimes appear contradictory, our data demonstrated they all play a role in tolerance and are apparent depending on the time, place and cohort of graft reactive cells under investigation. First, $T_{\text {reg }}$ presence is integral to long-term graft acceptance. Several models of tolerance induction including DST and anti-CD40L mAb therapy (32), DST and CD4 ${ }^{+}$cell depletion (50), rapamycin and TGF $\beta$ treatment (51), GITR blockade (52) and transfer of tolerogenic dendritic cells (53) induce the generation of $\mathrm{T}_{\text {reg. }}$. The finding that $\mathrm{T}_{\text {reg }}$ deletion overrides the graft-protective effects of DST and anti-CD40L $\mathrm{mAb}$ therapy following skin grafting (30) further underlines the importance of $\mathrm{T}_{\text {reg }}$ generation in tolerance. In seeming contrast to these findings, one study utilizing a cardiac allograft model demonstrated that DST plus anti-CD40L mAb results in the activation and then deletion of alloantigen-specific $\mathrm{CD}^{+}$cells, with no conversion to $\mathrm{T}_{\text {reg }}(11)$. However, the experimental protocol relied on depletion of endogenous $\mathrm{CD}^{+} \mathrm{T}$ cells before adoptive transfer of alloantigen-specific $\mathrm{T}$ cells and may have been dominated by lymphopenia and homeostatic proliferation. Our model removed this variable by transferring labeled alloreactive cells to a replete population of $\mathrm{CD} 4^{+}$cells, providing a more accurate reflection 
of T-cell responses. In our experiments, cells present at time of tolerance induction became $\mathrm{T}_{\text {reg, }}$, those transferred into tolerogen-treated recipients failed to differentiate into this phenotype, and cells transferred to rejecting recipients did not express Foxp3. Esposito et al. recently demonstrated that acquisition of Foxp3 expression did not necessarily in-- dicate $\mathrm{T}_{\text {reg }}$ function (54), whereas it is likely that the Foxp3 cells detected in our experiments possessed a regulatory phenotype. Day -7 graft reactive cells exposed to antigen in the absence of anti-CD40L therapy failed to express Foxp3, whereas day -7 graft reactive cells in tolerized mice acquired expression of this marker. Further, the Foxp $3^{+}$cytokine producing cells detected by Esposito et al. were $\mathrm{CD} 25^{-}$; the Foxp $3^{+}$cells detected here were $\mathrm{CD} 25^{+}$. Thus, although consideration should be made that these cells could be in a phase of effector differentiation, it is likely that they were $\mathrm{iT}_{\text {reg. }}$. These findings suggest that tolerance induction results in a population of Foxp $3^{+}$, regulatory, graft reactive cells and that the induction of tolerance prevents graft reactive cells transferred or generated at a later time from not only becoming activated, but also from becoming Foxp $3^{+}$. This effect is likely due to the environment in which the day 0 cells encounter antigen, as depletion of endogenous $\mathrm{T}_{\text {reg }}$ with anti-CD25 mAb or diphtheria toxin did not affect the fate of the day 0 cells transferred into tolerogentreated recipients. As an alternate explanation, $T_{\text {reg }}$ have recently been described to undergo rapid, functional reprogramming, characterized by switching from a suppressive phenotype to licensing cross-presentation and priming of naive CD8 ${ }^{+}$ cells by DC (55). This finding is of exceptional relevance to transplantation, as $\mathrm{CD} 8^{+}$cells drive unmodified acute allograft rejection $(13,56)$. This functional shift of $\mathrm{T}_{\text {reg }}$ was critically dependent upon CD40L expression (55), providing an interesting insight into and rationale for a potential mechanism of action of anti-CD40L mAb therapy.

A second hallmark of tolerance is T-cell anergy. In models of tolerance induction utilizing CTLA-4Ig therapy (7), ICOS blockade (57), PD-1 engagement (58) and rapamycin and cyclosporine A treatment $(59,60)$, graft reactive T-cell activation and/or proliferation was inhibited. In our experiments, this result was evident only in cells transferred at the time of transplantation to tolerogen-treated recipients. These cells neither proliferated nor became activated and were eventually deleted via apoptosis. Hence, our data support a model of functional tolerance in which potentially graft reactive cells exposed to alloantigen at the time of transplantation, but not at the time of initial tolerogen administration, remain in a quiescent or anergic state before apoptotic deletion.

AICD of graft reactive cells is a third common theme associated with tolerance $(29-31,61)$. Initiation of AICD is dependent on the timing and environment in which T cells first encounter their cognate antigen (29). Quezada et al. (30) demonstrated that antigen-specific cells transferred into a tolerant environment (DST and anti-CD40L mAb treated recipients) at the time of skin transplantation proliferated and became activated, but to a lesser extent than cells transferred into a nontolerant environment. DST and anti-CD40L mAb therapy resulted in clonal exhaustion of graft reactive cells following skin grafting (31), whereas these experiments were performed following cell transfer into $\mathrm{RA}^{--}$recipients and, therefore, were influenced by lymphopenia and homeostatic proliferation. In our experiments, graft reactive cells transferred at the time of DST treatment underwent a burst of proliferation, followed by contraction of this population, regardless of anti-CD40L mAb treatment. This contraction was due to AICD, as these cells expressed high levels of CD69 and CD44. In contrast, although cells transferred on day 0 at the time of transplantation underwent apoptosis, this cell death was not AICD as they were not activated. Thus, our observations show both AICD and non-AICD paths to apoptosis and tolerance, and resolve apparent contradictions among various reports due to model dependent differences between skin and cardiac allografts, temporal differences in cell cohort transfer during tolerance induction or transplantation, and/or lymphopenic or replete environments into which cells are transferred. 
Lastly, LN occupancy is necessary to generate alloantigen-specific tolerance (34) and regulatory cells (62). Day -7 cells in tolerogen-treated recipients expressed more Foxp3, and more of these Foxp3 ${ }^{+}$cells were located in the $\mathrm{LN}$ as compared to spleen. Our data also showed that although LN homing was important for tolerance induction, it was not sufficient for the continued generation of regulatory cells as forced LN occupancy by day 0 cells in a tolerant environment did not generate $\mathrm{T}_{\text {reg. }}$. Similarly, forcing day 0 cells out of the $\mathrm{LN}$ in a tolerant environment by blocking CD62L failed to restore day 0 cell proliferation and activation, suggesting that other tolerogenic influences remained functional. Space constraints alone did not inhibit day 0 cells from becoming $T_{\text {reg }}$, as depletion of endogenous $\mathrm{T}_{\text {reg }}$ did not result in the generation of Foxp $3^{+}$day 0 cells. These findings suggest that although $\mathrm{LN}$ occupancy is preferred for $\mathrm{T}_{\text {reg }}$ generation, the suppression of potentially graft re-active cells is not mediated exclusively within the LN.

Our data in concert with previously published reports suggest a detailed and complex system by which graft tolerance is attained. During the induction of tolerance, graft reactive cells become activated, proliferate, and differentiate into $\mathrm{T}_{\text {reg }}$ and seed the $\mathrm{LN}$ before a large portion of these cells are deleted via AICD. In contrast, graft reactive cells transferred into a tolerant environment become anergic before becoming apoptotic. Regardless of the timing of transfer, graft reactive cells in rejecting recipients become activated and proliferate, preferentially in the spleen, before undergoing AICD. Hence, by altering the timing and place of antigen presentation, otherwise homogeneous cohorts of cells have widely varied fates.

\section{Acknowledgments}

This work was supported by R01 AI041428, AI062765 and AI072039 (all to J.S.B.) and T32 AI078892 and HL007698 (to B.E.B.) from the National Institutes of Health.

\section{Abbreviations}

$\begin{array}{ll}\text { AICD } & \text { activation induced cell death } \\ \text { day }-7 \text { cells } & \text { graft reactive } \mathrm{CD}^{+} \mathrm{T} \text { cells transferred } 7 \text { days before transplantation } \\ \text { day } 0 \text { cells } & \text { graft reactive } \mathrm{CD}^{+} \mathrm{T} \text { cells transferred at the time of transplantation } \\ \text { DST } & \text { donor-specific splenocyte transfusion } \\ \text { i.v } & \text { intravenous } \\ \text { LN } & \text { lymph node } \\ \text { TCR } & \text { T-cell receptor } \\ \text { Tg } & \text { transgenic } \\ \text { Treg } & \text { regulatory suppressive T cells }\end{array}$

\section{References}

1. Zheng XX, Sanchez-Fueyo A, Domenig C, Strom TB. The balance of deletion and regulation in allograft tolerance. Immunol Rev. 2003; 196:75-84. [PubMed: 14617199]

2. Rothstein DM, Sayegh MH. T-cell costimulatory pathways in allograft rejection and tolerance. Immunol Rev. 2003; 196:85-108. [PubMed: 14617200]

3. Halloran PF. Immunosuppressive drugs for kidney transplantation. N Engl J Med. 2004; 351:27152729. [PubMed: 15616206] 
4. Knechtle SJ, Hamawy MM, Hu H, Fechner JH Jr, Cho CS. Tolerance and near-tolerance strategies in monkeys and their application to human renal transplantation. Immunol Rev. 2001; 183:205-213. [PubMed: 11782258]

5. Durrbach A, Francois H, Jacquet A, Beaudreuil S, Charpentier B. Co-signals in organ transplantation. Curr Opin Organ Transplant. 2010; 15:474-480. [PubMed: 20631615]

6. Vincenti F, Kirk AD. What's next in the pipeline. Am J Transplant. 2008; 8:1972-1981. [PubMed: 18828764]

7. Larsen CP, Elwood ET, Alexander DZ, et al. Long-term acceptance of skin and cardiac allografts after blocking CD40 and CD28 pathways. Nature. 1996; 381:434-438. [PubMed: 8632801]

8. Noelle RJ, Roy M, Shepherd DM, Stamenkovic I, Ledbetter JA, Aruffo A. A 39-kDa protein on activated helper T cells binds CD40 and transduces the signal for cognate activation of B cells. Proc Natl Acad Sci U S A. 1992; 89:6550-6554. [PubMed: 1378631]

9. Parker DC, Greiner DL, Phillips NE, et al. Survival of mouse pancreatic islet allografts in recipients treated with allogeneic small lymphocytes and antibody to CD40 ligand. Proc Natl Acad Sci U S A. 1995; 92:9560-9564. [PubMed: 7568172]

10. Hancock WW, Sayegh MH, Zheng XG, Peach R, Linsley PS, Turka LA. Costimulatory function and expression of CD40 ligand, CD80, and CD86 in vascularized murine cardiac allograft rejection. Proc Natl Acad Sci U S A. 1996; 93:13967-13972. [PubMed: 8943044]

11. van Maurik A, Fazekas de St Groth B, Wood KJ, Jones ND. Dependency of direct pathway CD4+ $\mathrm{T}$ cells on CD40-CD154 costimulation is determined by nature and microenvironment of primary contact with alloantigen. J Immunol. 2004; 172:2163-2170. [PubMed: 14764682]

12. Wood SC, Lu G, Burrell BE, Bishop DK. Transplant acceptance following anti-CD4 versus antiCD40L therapy: Evidence for differential maintenance of graft-reactive T cells. Am J Transplant. 2008; 8:2037-2048. [PubMed: 18828767]

13. Bishop DK, Chan Wood S, Eichwald EJ, Orosz CG. Immunobiology of allograft rejection in the absence of IFN-gamma: CD8+ effector cells develop independently of CD4+ cells and CD40CD40 ligand interactions. J Immunol. 2001; 166:3248-3255. [PubMed: 11207279]

14. Nathan MJ, Yin D, Eichwald EJ, Bishop DK. The immunobiology of inductive anti-CD40L therapy in transplantation: Allograft acceptance is not dependent upon the deletion of graftreactive T cells. Am J Transplant. 2002; 2:323-332. [PubMed: 12118853]

15. Taylor PA, Lees CJ, Waldmann H, Noelle RJ, Blazar BR. Requirements for the promotion of allogeneic engraftment by anti-CD154 (anti-CD40L) monoclonal antibody under nonmyeloablative conditions. Blood. 2001; 98:467-474. [PubMed: 11435318]

16. Sanchez-Fueyo A, Domenig C, Strom TB, Zheng XX. The complement dependent cytotoxicity (CDC) immune effector mechanism contributes to anti-CD154 induced immunosuppression. Transplantation. 2002; 74:898-900. [PubMed: 12364878]

17. Monk NJ, Hargreaves RE, Marsh JE, et al. Fc-dependent depletion of activated T cells occurs through CD40L-specific antibody rather than costimulation blockade. Nat Med. 2003; 9:12751280. [PubMed: 14502279]

18. Csencsits K, Burrell BE, Lu G, Eichwald EJ, Stahl GL, Bishop DK. The classical complement pathway in transplantation: Unanticipated protective effects of $\mathrm{C} 1 \mathrm{q}$ and role in inductive antibody therapy. Am J Transplant. 2008; 8:1622-1630. [PubMed: 18557731]

19. Scully R, Cobbold SP, Mellor AL, Wissing M, Arnold B, Waldmann H. A role for Th2 cytokines in the suppression of CD8+ T cell-mediated graft rejection. Eur J Immunol. 1997; 27:1663-1670. [PubMed: 9247575]

20. Takeuchi T, Lowry RP, Konieczny B. Heart allografts in murine systems: The differential activation of Th2-like effector cells in peripheral tolerance. Transplantation. 1992; 53:1281-1294. [PubMed: 1351322]

21. Blazar BR, Taylor PA, Panoskaltsis-Mortari A, et al. Blockade of CD40 ligand-CD40 interaction impairs CD4+ T cell-mediated alloreactivity by inhibiting mature donor T cell expansion and function after bone marrow transplantation. J Immunol. 1997; 158:29-39. [PubMed: 8977172]

22. Larsen CP, Alexander DZ, Hollenbaugh D, et al. CD40-gp39 interactions play a critical role during allograft rejection: Suppression of allograft rejection by blockade of the CD40-gp39 pathway. Transplantation. 1996; 61:4-9. [PubMed: 8560571] 
23. Lu L, Li W, Zhong C, et al. Increased apoptosis of immunoreactive host cells and augmented donor leukocyte chimerism, not sustained inhibition of B7 molecule expression are associated with prolonged cardiac allograft survival in mice preconditioned with immature donor dendritic cells plus anti-CD40L mAb. Transplantation. 1999; 68:747-757. [PubMed: 10515374]

24. Dey B, Yang YG, Preffer F, et al. The fate of donor T-cell receptor transgenic T cells with known host antigen specificity in a graft-versus-host disease model. Transplantation. 1999; 68:141-149. [PubMed: 10428282]

25. Grubin CE, Kovats S, deRoos P, Rudensky AY. Deficient positive selection of CD4 T cells in mice displaying altered repertoires of MHC class II-bound self-peptides. Immunity. 1997; 7:197-208. [PubMed: 9285405]

26. Corry RJ, Winn HJ, Russell PS. Primarily vascularized allografts of hearts in mice: The role of H-2D, H-2K, and non-H-2 antigens in rejection. Transplantation. 1973; 16:343-350. [PubMed: 4583148]

27. Coomes SM, Wilke CA, Moore TA, Moore BB. Induction of TGF-beta 1, not regulatory T cells, impairs antiviral immunity in the lung following bone marrow transplant. J Immunol. 2010; 184:5130-5140. [PubMed: 20348421]

28. Itoh M, Takahashi T, Sakaguchi N, et al. Thymus and autoimmunity: Production of CD25+CD4+ naturally anergic and suppressive $\mathrm{T}$ cells as a key function of the thymus in maintaining immunologic self-tolerance. J Immunol. 1999; 162:5317-5326. [PubMed: 10228007]

29. Catron DM, Rusch LK, Hataye J, Itano AA, Jenkins MK. CD4+ T cells that enter the draining lymph nodes after antigen injection participate in the primary response and become centralmemory cells. J Exp Med. 2006; 203:1045-1054. [PubMed: 16567390]

30. Quezada SA, Bennett K, Blazar BR, Rudensky AY, Sakaguchi S, Noelle RJ. Analysis of the underlying cellular mechanisms of anti-CD154-induced graft tolerance: The interplay of clonal anergy and immune regulation. J Immunol. 2005; 175:771-779. [PubMed: 16002673]

31. Quezada SA, Fuller B, Jarvinen LZ, et al. Mechanisms of donor-specific transfusion tolerance: Preemptive induction of clonal T-cell exhaustion via indirect presentation. Blood. 2003; 102:1920-1926. [PubMed: 12750162]

32. Verbinnen B, Billiau AD, Vermeiren J, et al. Contribution of regulatory T cells and effector T cell deletion in tolerance induction by costimulation blockade. J Immunol. 2008; 181:1034-1042. [PubMed: 18606655]

33. Blair PJ, Riley JL, Harlan DM, et al. CD40 ligand (CD154) triggers a short-term CD4(+) T cell activation response that results in secretion of immunomodulatory cytokines and apoptosis. J Exp Med. 2000; 191:651-660. [PubMed: 10684857]

34. Bai Y, Liu J, Wang Y, et al. L-selectin-dependent lymphoid occupancy is required to induce alloantigen-specific tolerance. J Immunol. 2002; 168:1579-1589. [PubMed: 11823485]

35. Long E, Wood KJ. Regulatory T cells in transplantation: Transferring mouse studies to the clinic. Transplantation. 2009; 88:1050-1056. [PubMed: 19898199]

36. Adeegbe D, Levy RB, Malek TR. Allogeneic T regulatory cell-mediated transplantation tolerance in adoptive therapy depends on dominant peripheral suppression and central tolerance. Blood. 2010; 115:1932-1940. [PubMed: 20040758]

37. Joffre O, Santolaria T, Calise D, et al. Prevention of acute and chronic allograft rejection with CD4+CD25+Foxp3 +regulatory T lymphocytes. Nat Med. 2008; 14:88-92. [PubMed: 18066074]

38. Kingsley CI, Karim M, Bushell AR, Wood KJ. CD25+CD4+ regulatory T cells prevent graft rejection: CTLA-4- and IL-10-dependent immunoregulation of alloresponses. J Immunol. 2002; 168:1080-1086. [PubMed: 11801641]

39. Van Hoffen E, Van Wichen DF, Leemans JC, et al. T cell apoptosis in human heart allografts: Association with lack of co-stimulation? Am J Pathol. 1998; 153:1813-1824. [PubMed: 9846972]

40. Katakai T, Hara T, Lee JH, Gonda H, Sugai M, Shimizu A. A novel reticular stromal structure in lymph node cortex: An immuno-platform for interactions among dendritic cells, T cells and B cells. Int Immunol. 2004; 16:1133-1142. [PubMed: 15237106]

41. Lakkis FG, Arakelov A, Konieczny BT, Inoue Y. Immunologic 'ignorance' of vascularized organ transplants in the absence of secondary lymphoid tissue. Nat Med. 2000; 6:686-688. [PubMed: 10835686] 
42. Hara M, Chosa E, Onitsuka T. The spleen's role in transplantation immunology. Transpl Immunol. 2008; 18:324-329. [PubMed: 18158118]

43. Krammer PH, Arnold R, Lavrik IN. Life and death in peripheral T cells. Nat Rev Immunol. 2007; 7:532-542. [PubMed: 17589543]

44. Moon JJ, Chu HH, Pepper M, et al. Naive CD4(+) T cell frequency varies for different epitopes and predicts repertoire diversity and response magnitude. Immunity. 2007; 27:203-213. [PubMed: 17707129]

45. Hataye J, Moon JJ, Khoruts A, Reilly C, Jenkins MK. Naive and memory CD4+ T cell survival controlled by clonal abundance. Science. 2006; 312:114-116. [PubMed: 16513943]

46. Ariga H, Shimohakamada Y, Nakada M, et al. Instruction of naive CD4+ T-cell fate to T-bet expression and T helper 1 development: Roles of T-cell receptor-mediated signals. Immunology. 2007; 122:210-221. [PubMed: 17490433]

47. Mallone R, Kochik SA, Reijonen H, et al. Functional avidity directs T-cell fate in autoreactive CD4+ T cells. Blood. 2005; 106:2798-2805. [PubMed: 16030184]

48. Malherbe L, Filippi C, Julia V, et al. Selective activation and expansion of high-affinity CD4+ T cells in resistant mice upon infection with Leishmania major. Immunity. 2000; 13:771-782. [PubMed: 11163193]

49. Pepper M, Linehan JL, Pagan AJ, et al. Different routes of bacterial infection induce long-lived TH1 memory cells and short-lived TH17 cells. Nat Immunol. 2010; 11:83-89. [PubMed: 19935657]

50. Francis RS, Feng G, Tha-In T, Lyons IS, Wood KJ, Bushell A. Induction of transplantation tolerance converts potential effector T cells into graft-protective regulatory T cells. Eur J Immunol. 2011; 41:726-738. [PubMed: 21243638]

51. Zhang W, Zhang D, Shen M, et al. Combined administration of a mutant TGF-beta1/Fc and rapamycin promotes induction of regulatory T cells and islet allograft tolerance. J Immunol. 2010; 185:4750-4759. [PubMed: 20844194]

52. Sonawane SB, Kim JI, Lee MK, et al. GITR blockade facilitates Treg mediated allograft survival. Transplantation. 2009; 88:1169-1177. [PubMed: 19935370]

53. Thomson AW, Turnquist HR, Zahorchak AF, Raimondi G. Tolerogenic dendritic cell-regulatory T-cell interaction and the promotion of transplant tolerance. Transplantation. 2009; 87(9 Suppl):S86-S90. [PubMed: 19424018]

54. Esposito M, Ruffini F, Bergami A, et al. IL-17- and IFN-gamma-secreting Foxp3+ T cells infiltrate the target tissue in experimental autoimmunity. J Immunol. 2010; 185:7467-7473. [PubMed: 21098230]

55. Sharma MD, Hou DY, Baban B, et al. Reprogrammed foxp3(+) regulatory T cells provide essential help to support cross-presentation and CD8(+) T cell priming in naive mice. Immunity. 2010; 33:942-954. [PubMed: 21145762]

56. Bishop DK, Shelby J, Eichwald EJ. Mobilization of T lymphocytes following cardiac transplantation: Evidence that CD4-positive cells are required for cytotoxic T lymphocyte activation, inflammatory endothelial development, graft infiltration, and acute allograft rejection. Transplantation. 1992; 53:849-857. [PubMed: 1533070]

57. Ozkaynak E, Gao W, Shemmeri N, et al. Importance of ICOS-B7RP-1 costimulation in acute and chronic allograft rejection. Nat Immunol. 2001; 2:591-596. [PubMed: 11429542]

58. Freeman GJ, Long AJ, Iwai Y, et al. Engagement of the PD-1 immunoinhibitory receptor by a novel B7 family member leads to negative regulation of lymphocyte activation. J Exp Med. 2000; 192:1027-1034. [PubMed: 11015443]

59. Li Y, Li XC, Zheng XX, Wells AD, Turka LA, Strom TB. Blocking both signal 1 and signal 2 of T-cell activation prevents apoptosis of alloreactive T cells and induction of peripheral allograft tolerance. Nat Med. 1999; 5:1298-1302. [PubMed: 10545997]

60. Bestard O, Cassis L, Cruzado JM, et al. Costimulatory blockade with mTor inhibition abrogates effector T-cell responses allowing regulatory T-cell survival in renal transplantation. Transpl Int. 2011; 5:451-460. [PubMed: 21294788] 
61. Chau LA, Rohekar S, Wang JJ, et al. Thymic reentry of mature activated T cells and increased negative selection in vascularized allograft recipients. Clin Exp Immunol. 2002; 127:43-52. [PubMed: 11882031]

62. Ochando JC, Yopp AC, Yang Y, et al. Lymph node occupancy is required for the peripheral development of alloantigen-specific Foxp3 +regulatory T cells. J Immunol. 2005; 174:6993-7005. [PubMed: 15905542] 
A

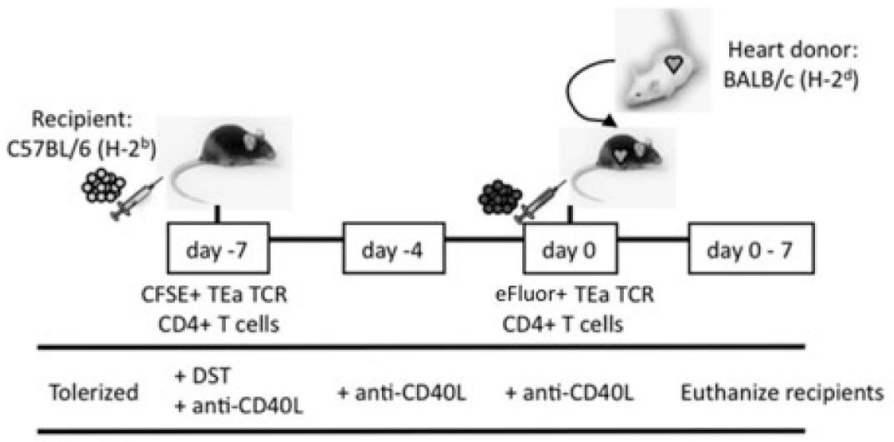

Rejecting - . . Euthanize recipients

B

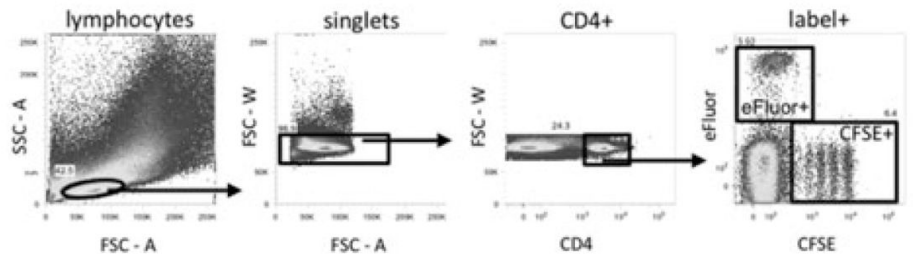

C
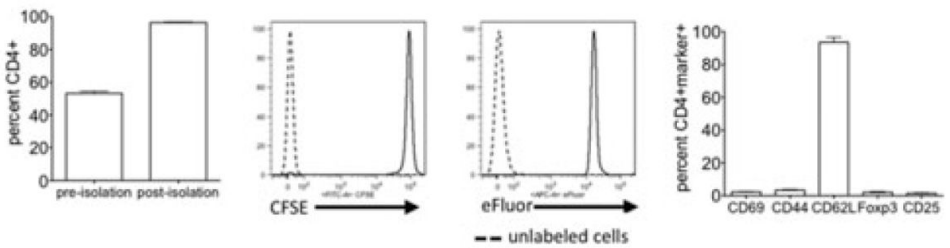

- labeled cells

Figure 1. Isolation and transfer of naive alloantigen-specific $\mathrm{CD4}^{+} \mathrm{T}$ cells to track the fate of alloreactive cells in cardiac al-lograft recipients

(A) C57BL/6 recipients received $2 \times 10^{7}$ CFSE-labeled TEa TCR Tg CD4 ${ }^{+}$cells 7 days before transplant (day -7 ). On the day of transplantation (day 0), recipients received $2 \times 10^{7}$ eFluor-labeled TEa TCR Tg CD4 ${ }^{+} \mathrm{T}$ cells along with a BALB/c cardiac allograft. Tolerized mice were given $10^{7} \mathrm{BALB} / \mathrm{c}$ splenocytes (DST) i.v. on day -7 and $250 \mu \mathrm{g}$ anti-CD40L $\mathrm{mAb}$ on days $-7,-4,0$ and +4 relative to transplant. Rejecting control mice were left untreated. Recipients were euthanized 0-7 days posttrans-plant. (B) Gating scheme. Flow cytometric dot plots were gated on label ${ }^{+} \mathrm{CD} 4^{+}$singlet lymphocytes. Representative staining of splenic lymphocytes is depicted. (C) Purity, labeling and phenotype of cells pre-transfer. TEa TCR Tg CD4 ${ }^{+} \mathrm{T}$ cells were enriched from the spleen and $\mathrm{LN}$ of TEa mice as described in Materials and Methods. Percentage of cells that were $\mathrm{CD}^{+}$before and after isolation (left panel) and representative relative fluorescence histograms after labeling with CFSE (middle left panel) and eFluor (middle right panel) are shown $(n=28)$. The naive phenotype of transferred cells was confirmed by the presence or absence, as appropriate, of CD69, CD44, CD62L, Foxp3 and CD25 (right panel, $n=3$ ). 

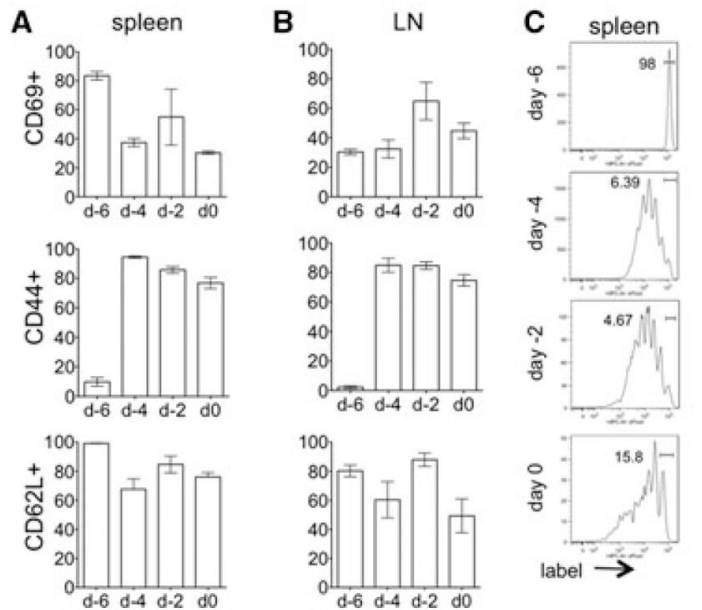

E $\quad$ CD 45.2+
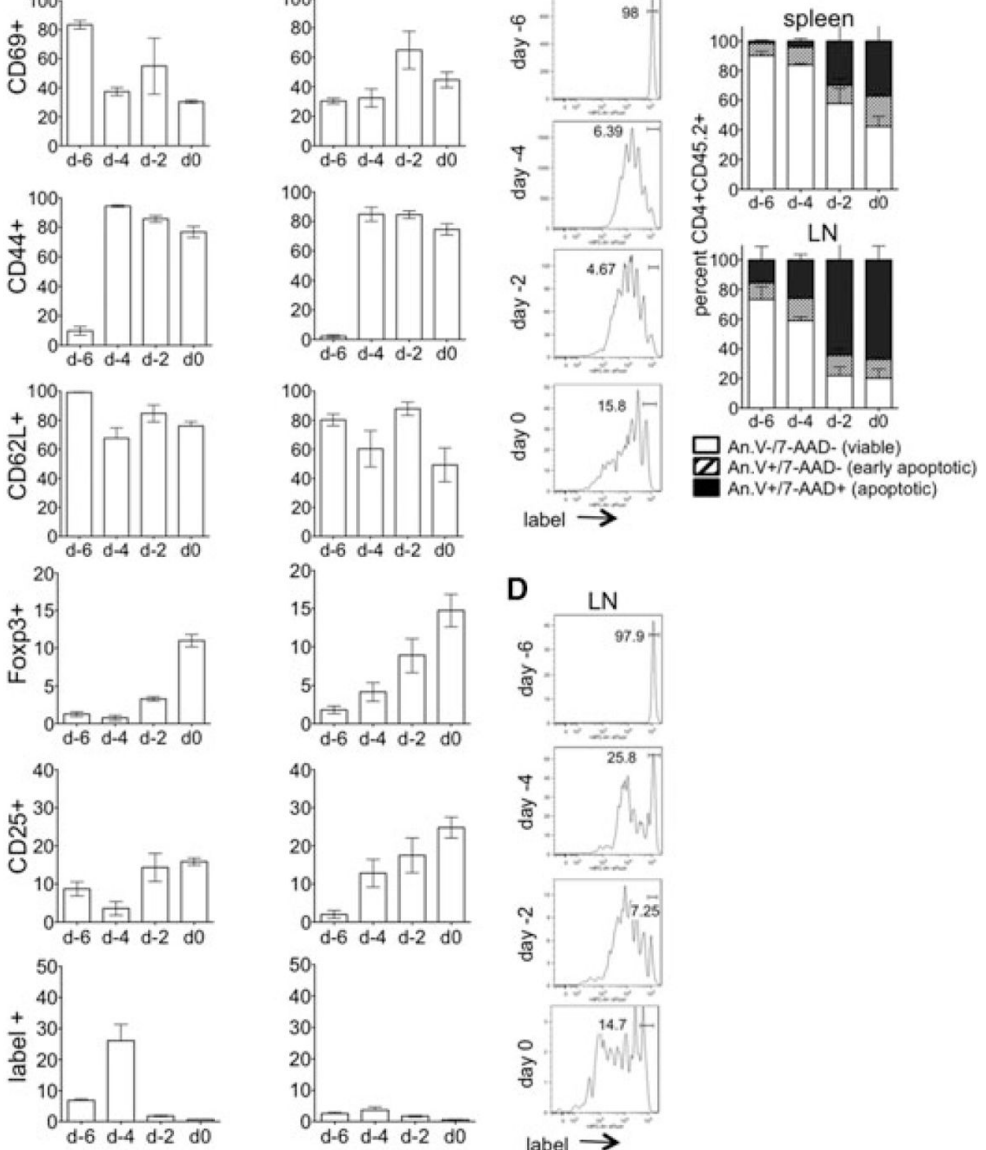

days pre-transplant
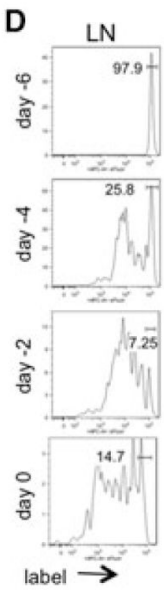

\begin{tabular}{|l|l|} 
tolerized recipients & \\
\hline TEa Tg T cell transfer & day -7 \\
\hline DST administration & day -7 \\
\hline anti-CD 40 L therapy & days $-7,-4,0$ \\
\hline euthanasi a & days $-6,-4,-2,0$ \\
\hline
\end{tabular}

Figure 2. Graft reactive cells proliferate and become activated in response to treatment with DST and anti-CD40L mAb before transplantation

(A-D) $\mathrm{CD} 4^{+} \mathrm{TEa}$ cells $\left(\mathrm{CD} 45.2^{+}\right)$were isolated, labeled with eFluor and transferred to tolerogen (DST + anti-CD40L mAb) treated congenic CD45.1+ C57BL/6 mice at day -7 . Recipients were euthanized on days $-6,-4,-2$ and 0 , and CD45.2+CD4+label+ splenocytes (A, C) and LN lymphocytes (B, D) analyzed for CD69, CD44, CD62L, Foxp3 and CD25 and for proliferation by label dilution. (E) For apoptosis, total transferred TEa cells $\left(\mathrm{CD} 45.2^{+}\right)$were recovered from the spleen and $\mathrm{LN}$ and analyzed by annexin $\mathrm{V}$ and 7-AAD staining on days $-6,-4,-2$ and 0 . Data represent of 4 mice/group. Experimental conditions are outlined in the accompanying table. 

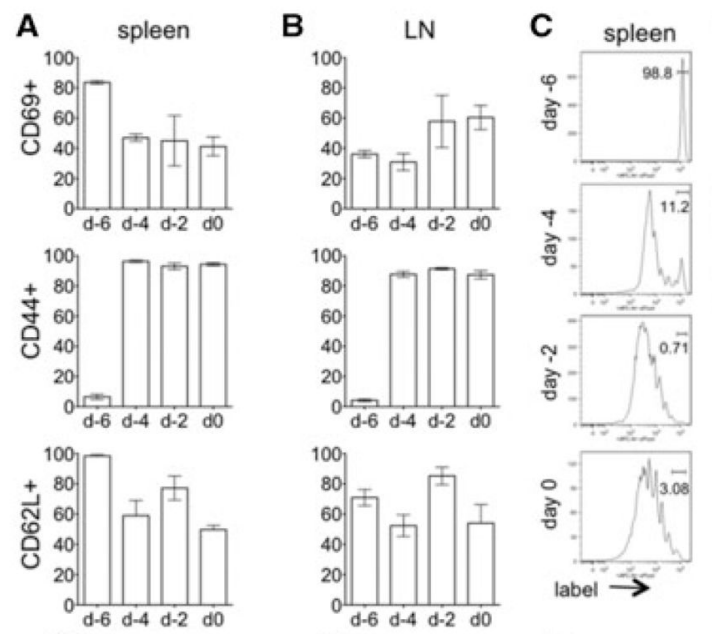

E $\begin{gathered}\mathrm{CD} 45.2+ \\ \text { spleen }\end{gathered}$
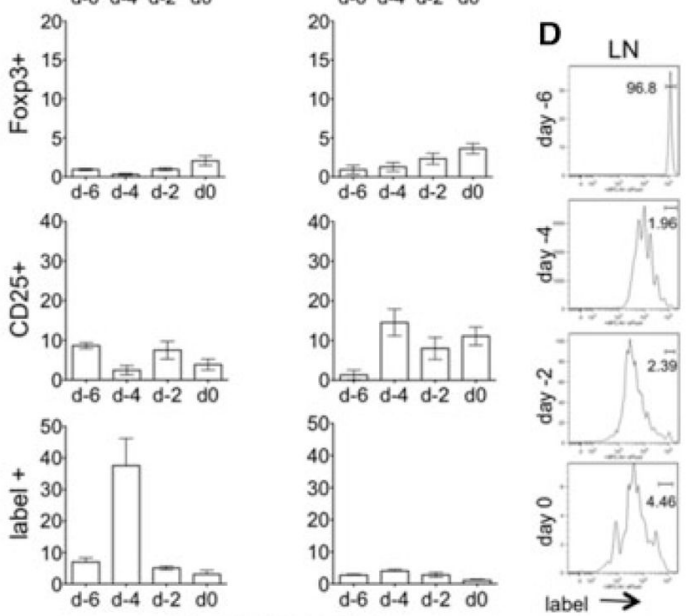

days pre-transplant

\begin{tabular}{|l|l|} 
rejecting recipients & \\
\hline TEa Tg T cell transfer & day -7 \\
\hline DST administration & day -7 \\
\hline anti-CD40L therapy & none \\
\hline euthanasi a & days $-6,-4,-2,0$ \\
\hline
\end{tabular}

Figure 3. Graft reactive cells proliferate and become activated in response to treatment with DST alone

(A-D) $\mathrm{CD} 4^{+}$TEa cells $\left(\mathrm{CD} 45.2^{+}\right)$were isolated, labeled with eFluor and transferred to DST-treated congenic CD45.1+ C57BL/6 mice at day -7. Recipients were euthanized on days $-6,-4,-2$, and 0 and CD45.2+CD4+label+ splenocytes (A, C) and LN lymphocytes (B, D) analyzed for CD69, CD44, CD62L, Foxp3 and CD25, and for proliferation by label dilution. (E) For apoptosis, total transferred TEa cells $\left(\mathrm{CD} 45.2^{+}\right)$were recovered from the spleen and LN and analyzed by annexin $\mathrm{V}$ and 7-AAD staining on days $-6,-4,-2$ and 0 . Data represent of 4 mice/group. Experimental conditions are outlined in the accompanying table. 

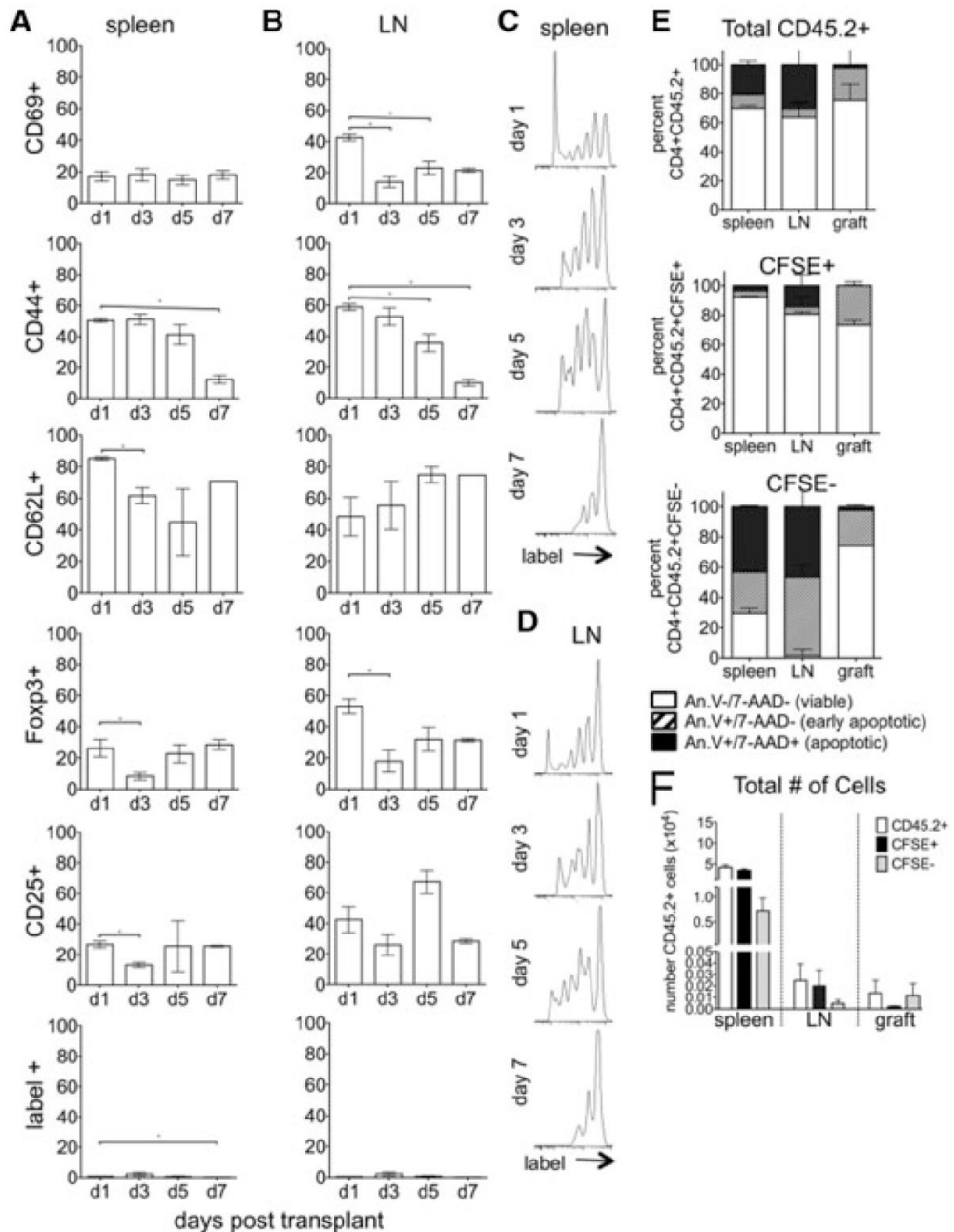

days post transplant

\begin{tabular}{|l|l|} 
tolerized recipients & \\
\hline TEa Tg T cell tran sfer & day -7 \\
\hline DST administration & day -7 \\
\hline anti-CD40L therapy & days $-7,-4,0,+4$ \\
\hline transplantation & day 0 \\
\hline euthanasia & days $+1,+3,+5,+7$ \\
\hline
\end{tabular}

Figure 4. Graft reactive cells transferred at day -7 undergo phenotypic changes in response to tolerance induction

(A-D) $\mathrm{CD}^{+}$TEa cells were isolated, labeled with CSFE and transferred to tolerogen (DST and anti-CD40L mAb) treated C57BL/6 allograft recipients at day -7 relative to transplant. Recipients were euthanized on days 1, 3,5 and 7 and CD4+label+ splenocytes (A, C) and LN lymphocytes (B, D) analyzed for CD69, CD44, CD62L, Foxp3 and CD25 and for proliferation by label dilution. (E) For apoptosis, congenic recipients $\left(\mathrm{CD} 45.1^{+}\right)$received TEa cells $\left(\mathrm{CD} 45.2^{+}\right)$on day -7 and were euthanized day 1 posttransplantation, day 8 postexperimental onset. Total transferred TEa cells (CD45.2 $2^{+}$, top), TEa cells that maintained their label $\left(\mathrm{CFSE}^{+}\right.$, middle), and TEa cells that proliferated sufficiently to lose their label ( $\mathrm{CFSE}^{-}$, bottom) were recovered from the spleen, $\mathrm{LN}$ and graft and analyzed by annexin $\mathrm{V}$ and 7-AAD staining. (F) The total number of $\mathrm{CD} 45.2^{+}, \mathrm{CFSE}^{+}$and $\mathrm{CFSE}^{-}$cells recovered from the spleens, $\mathrm{LN}$ and grafts and analyzed in (E) are represented. $\mathrm{p}<0.05$. Data represent of 3-8 transplanted mice/group. Experimental conditions are outlined in the accompanying table. 


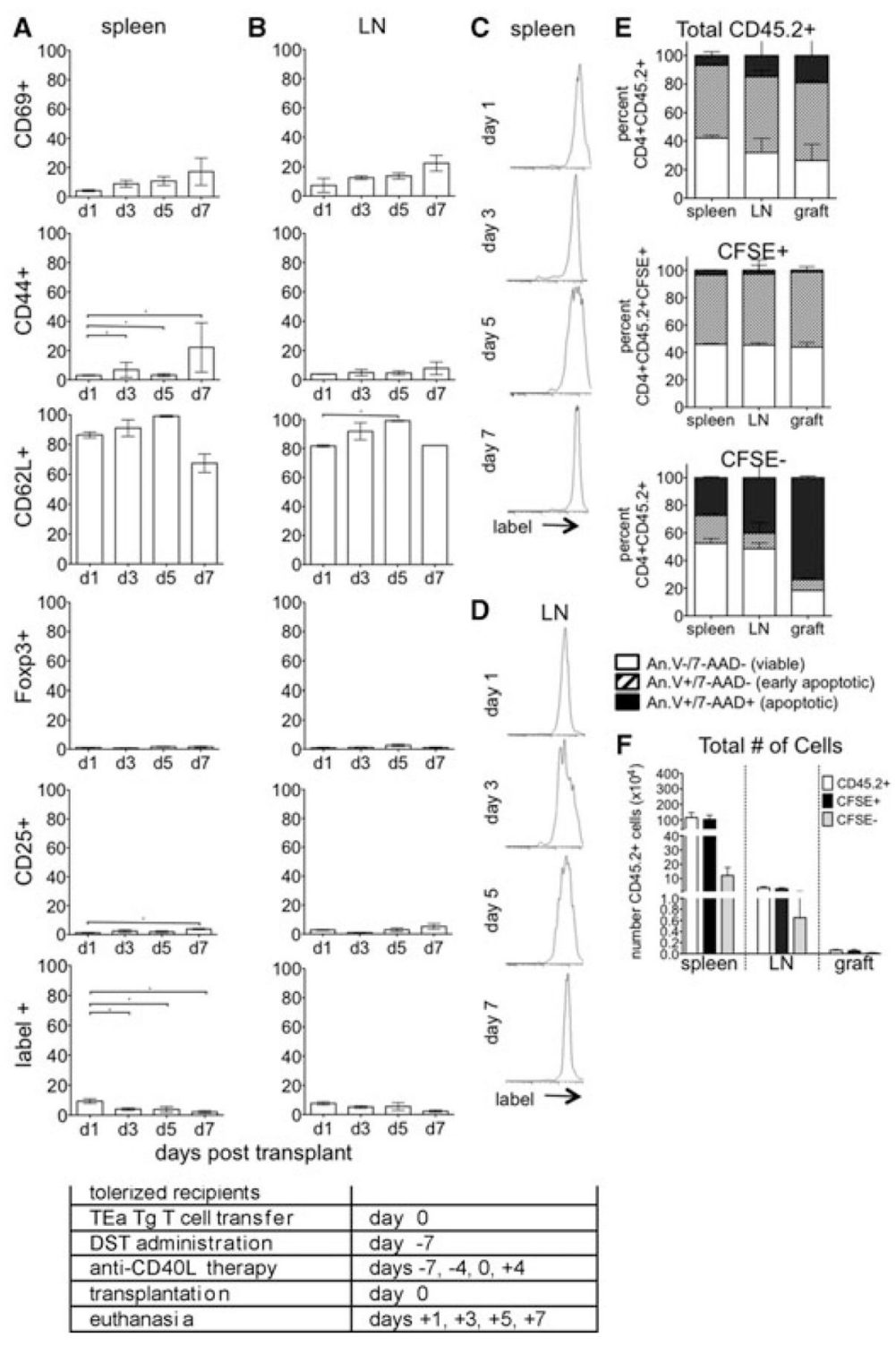

Figure 5. Graft reactive cells exposed to antigen in a tolerant environment do not become activated

eFluor labeled $\mathrm{CD}^{+}{ }^{+} \mathrm{TEa}$ cells were transferred to tolerized recipients on the day of transplantation (day 0). Recipients were euthanized at days 1, 3, 5 and 7 and CD4+label+ splenocytes (A, C) and LN lymphocytes (B, D) analyzed for (A, B) ac- tivation and $\mathrm{T}_{\text {reg }}$ conversion, (C, D) proliferation and (E) apoptosis as in Figure 3. (F) The total number of CD45.2 $2^{+}, \mathrm{CFSE}^{+}$and $\mathrm{CFSE}^{-}$cells recovered from the spleens, $\mathrm{LN}$ and grafts (5 days postday 0 cell transfer, 13 days postexperimental onset) and analyzed in (E) are represented. $\mathrm{p}<$ 0.05. Data represent of 3-8 transplanted mice/group. Experimental conditions are outlined in the accompanying table. 

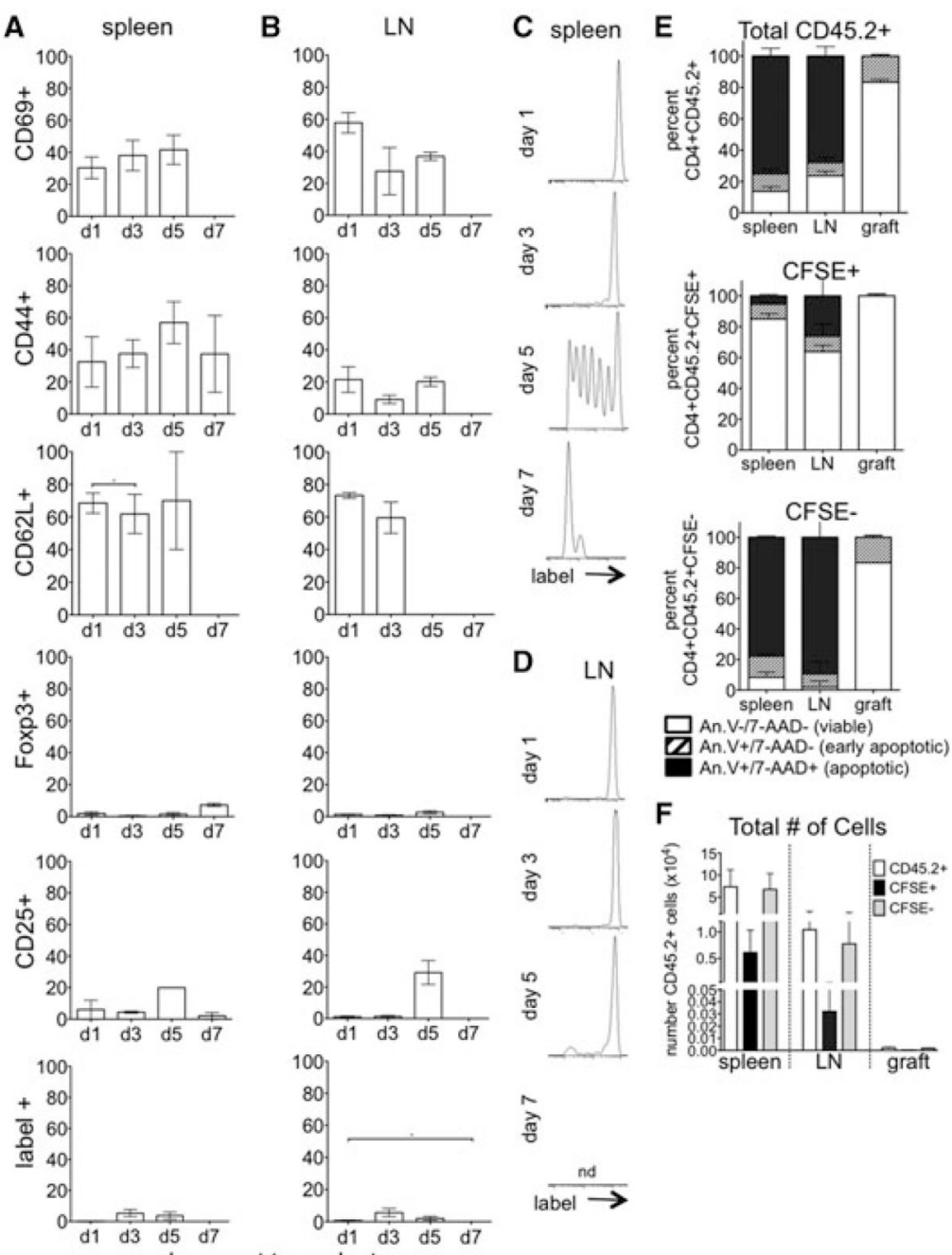

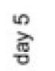

days post transplant

\begin{tabular}{|l|l|} 
rejecting recipients & \\
\hline TEa Tg T cell transfer & day -7 \\
\hline DST administration & none \\
\hline anti-CD40L therapy & none \\
\hline transplantation & day 0 \\
\hline euthanasia & days $+1,+3,+5,+7$ \\
\hline
\end{tabular}

Figure 6. Graft reactive cells transferred at day -7 undergo phenotypic changes in response to rejection

CFSE labeled CD4 ${ }^{+}$TEa cells were transferred to untreated allograft recipients at day -7 .

Recipients were euthanized at days 1, 3, 5 and 7 and CD4+label+ splenocytes (A, C) and LN lymphocytes (B, D) analyzed for (A, B) activation and $\mathrm{T}_{\text {reg }}$ conversion, (C, D) proliferation and (E) apoptosis as in Figure 3. (F) The total number of CD45.2 ${ }^{+}, \mathrm{CFSE}^{+}$and $\mathrm{CFSE}^{-}$cells recovered from the spleens, $\mathrm{LN}$ and grafts (8 days pos-texperimental onset) and analyzed in (E) are represented. nd, insufficient cell number to provide accurate proliferative data; $p<$ 0.05 . Data represent of 3-8 transplanted mice/group. Experimental conditions are outlined in the accompanying table. 

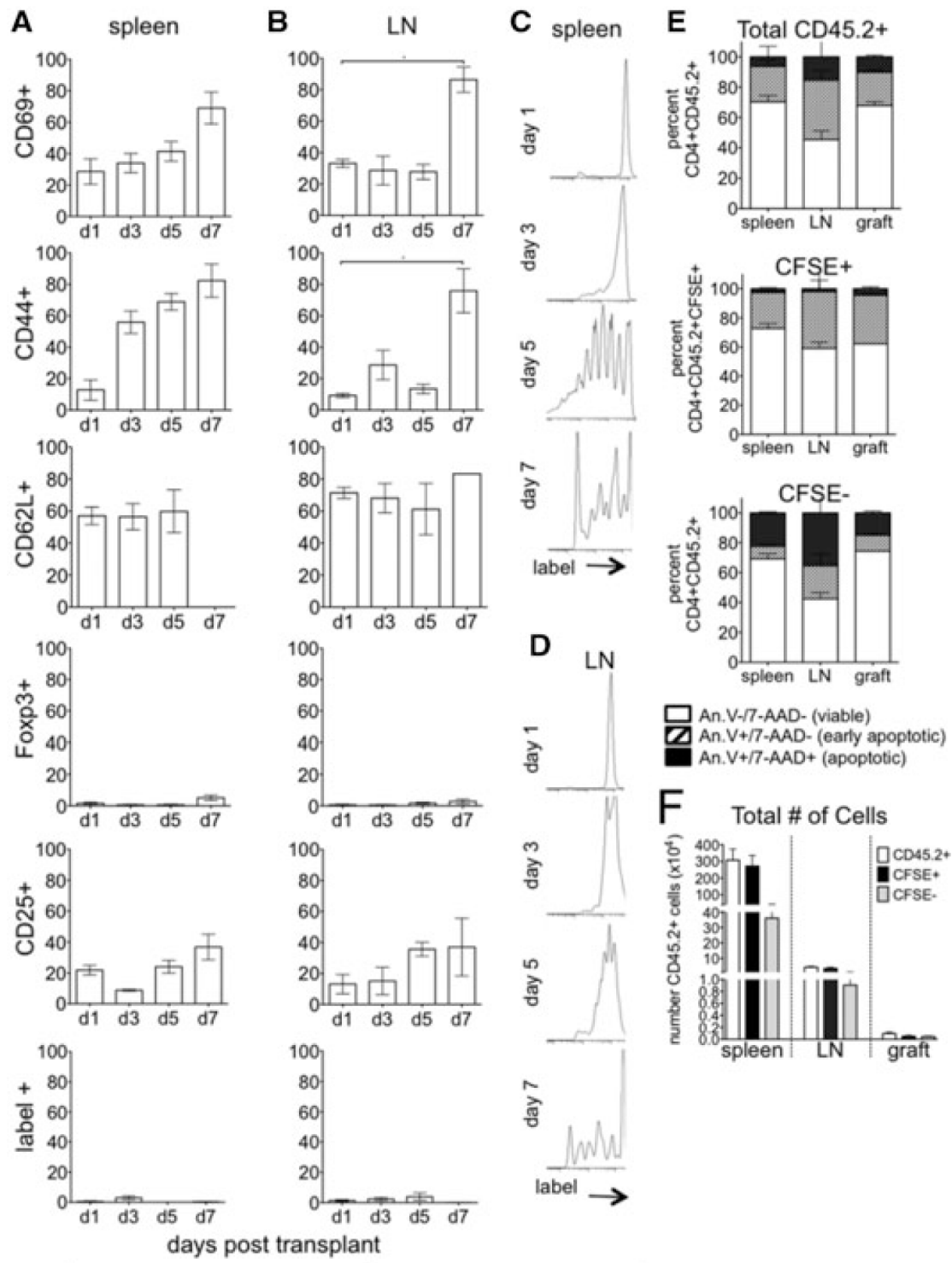

\begin{tabular}{|l|l|} 
rejecting recipients & \\
\hline TEa Tg T cell tran sfer & day 0 \\
\hline DST administration & none \\
\hline anti-CD40L therapy & none \\
\hline transplantation & day 0 \\
\hline euthanasia & days $+1,+3,+5,+7$ \\
\hline
\end{tabular}

Figure 7. Graft reactive cells transferred at the time of transplantation undergo phenotypic changes in response to rejection

eFluor labeled $\mathrm{CD}^{+}{ }^{+} \mathrm{TEa}$ cells were transferred to untreated recipients on the day of transplantation (day 0). Recipients were euthanized at days 1,3,5 and 7 and CD4+label+ splenocytes (A, C) and LN lymphocytes (B, D) analyzed for (A, B) activation and $\mathrm{T}_{\text {reg }}$ conversion, (C, D) proliferation and (E) apoptosis as in Figure 3. (F) The total number of $\mathrm{CD}^{4} 5.2^{+}, \mathrm{CFSE}^{+}$and $\mathrm{CFSE}^{-}$cells recovered from the spleens, $\mathrm{LN}$ and grafts (5 days postday 0 cell transfer, 13 days postexperimental onset) and analyzed in (E) are represented. p < 0.05. Data represent of 3-8 transplanted mice/group. Experimental conditions are outlined in the accompanying table. 
A

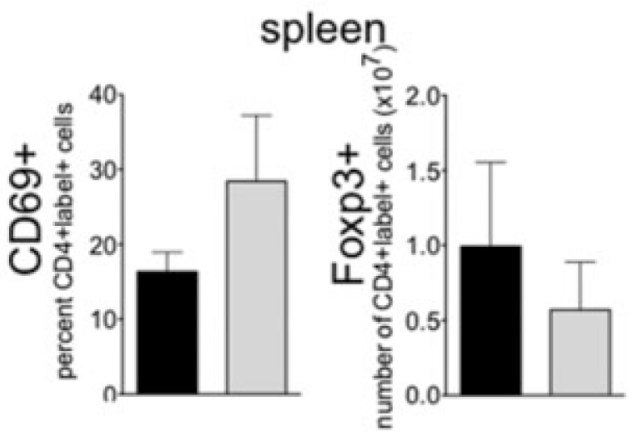

DST + anti-CD40L

DST + anti-CD40L + anti-CD62L

\begin{tabular}{|l|l|} 
tolerized recipients & \\
\hline TEa Tg T cell transfer & day 0 \\
\hline DST administration & days $-7,0$ \\
\hline anti-CD40L therapy & days $-7,-4,0,+4$ \\
\hline anti-CD62L treatment & days $0,+1$ \\
\hline euthanasia & day +7 \\
\hline
\end{tabular}

B

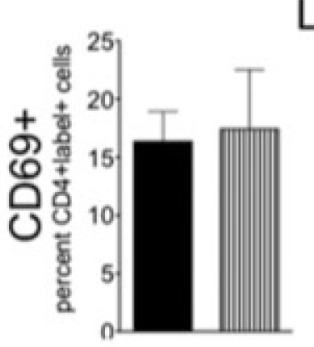

LN

DST + anti-CD40L

而DST + anti-CD40L + FTY720

\begin{tabular}{|l|l|} 
tolerized recipients & \\
\hline$T E a T g T$ cell transfer & day 0 \\
\hline DST administration & days $-7,0$ \\
\hline anti-CD40L therapy & days $-7,-4,0,+4$ \\
\hline FTY720 treatment & days 0 through +6 \\
\hline euthanasia & day +7 \\
\hline
\end{tabular}

Figure 8. Lymph node occupancy does not guarantee activation or Foxp3 expression by graft reactive cells transferred at day 0

Tolerance was induced on day -7 , and on day 0 mice received another dose of DST and transfer of eFluor labeled TEa cells. Recipients were euthanized 7 days after the second DST, 14 days after the onset of the experiment, and cells transferred on day 0 found in the spleen and LN were analyzed for expression of CD69 and Foxp3. Recipients additionally received anti-CD62L mAb on days 0 and 1 (100 $\mu \mathrm{g} / \mathrm{dose}$, gray bars) or FTY720 daily from day 0-6 (25 $\mu \mathrm{g} / \mathrm{dose}$, striped bars). Data are represented as the total number or percentage of the indicated cells recovered from spleen or LN. $n=5$ mice for each condition, $p>0.05$ for all data sets. Experimental conditions are outlined in the accompanying tables. 